\title{
Valorization of rice by-products: Protein-phenolic based fractions with bioactive potential
}

\author{
Y.A. Rodríguez-Restrepo ${ }^{\text {a,b }}$, P. Ferreira-Santos ${ }^{\text {a }}$, C.E. Orrego ${ }^{c}$, J.A. Teixeira ${ }^{a}$, C.M.R. Rocha ${ }^{\text {a,* }}$ \\ ${ }^{a}$ Centre of Biological Engineering, University of Minho, Campus Gualtar, 4710-057, Braga, Portugal \\ ${ }^{\mathrm{b}}$ Instituto de Biotecnología y Agroindustria, Departamento de Ingeniería Química, Universidad Nacional de Colombia, Sede Manizales, Campus la Nubia Km 7 Vía al \\ Magdalena, AA 127, Manizales, Colombia \\ ${ }^{\mathrm{c}}$ Instituto de Biotecnología y Agroindustria, Departamento de Física y Química, Universidad Nacional de Colombia Sede Manizales, Campus la Nubia Km 7 Vía al \\ Aeropuerto, AA 127, Manizales, Colombia
}

\section{A R T I C L E I N F O}

\section{Keywords:}

Rice bran protein

Protein extracts and hydrolysates

Phenolic compounds

Antioxidant activity

\begin{abstract}
A B S T R A C T
Rice bran (RB) is an important by-product from the rice production with a high valorization potential. The aim of the present work was to explore this potential by considering combined protein and phenolic fractions and enzymatic hydrolysis. The influence of different protocols in the recovery/fractioning of protein were evaluated, including defatting procedures, in rice brans from two very different locations: Portugal and Colombia. The different protein fractions achieved were characterized. Proteins were further hydrolyzed using trypsin and their hydrolysates were characterized in terms of degree of hydrolysis and peptide size. Moreover, the total phenolic content (TPC) and phenolic compounds' profile on extracted fractions and hydrolysates of RB from Portugal and Colombia were determined. The functional potential was assessed in terms of antioxidant and antihypertensive activities. Though the protein concentrates had already significant potential bioactivities, protein hydrolysates showed that the TPC, antioxidant and antihypertensive activities significantly increased with the digestion by trypsin. Hydrolysates of RB from Portugal presented a higher antioxidant and hypertensive activities in comparison with hydrolysates of RB from Colombia, moreover it presented a higher content of TPC. This study indicated that the exploitation potential of rice bran can be increased with simple fractioning procedures, that combined protein/phenolic fractions are important to deliver functionality and that hydrolysis can be a relevant tool to release that functionality. Furthermore, regional differences in rice bran composition are also important factors to consider. Overall, this knowledge can be used to increase the industrial potential of valorization for this by-product.
\end{abstract}

\section{Introduction}

Rice is one of the most important food consumed in the world. About 610 million metric tons of rice is produced annually (Wang et al., 2017). During the milling of rice, two kinds of by-products are generated: rice husk and rice bran, which are equivalent to the $20-25 \%$ and $10 \%$ of the unpeeled grain weight, respectively (Thamnarathip et al., 2016). The rice bran (RB) is a relatively cheap by-product. It is considered a rich source of bioactive compounds, it has the potential to be used as a food ingredient. The protein concentration in $\mathrm{RB}$ and defatted rice bran (RBD) can vary between $12-15 \%$ and $15-17 \%$, respectively (Kaewka et al., 2009). This by-product is very rich in proteins such as albumin (12.5-43- \%), globulin (13-36\%), prolamin (1-5\%) and, in higher proportion, glutelin (22-45\%) (Wattanasiritham et al., 2016; Amagliani et al., 2017a).

Due to the high concentration of proteins, RB can be considered as an attractive raw material for the production of hydrolysates with potential biological activity. In fact, several research groups have reported peptides from rice bran protein with bioactive features, demonstrating the high-value potential of the protein from this by-product (Uraipong and Zhao, 2016; Wang et al., 2017).

Enzymatic hydrolysis exposes antioxidant amino acids trough the formation of peptides with different characteristics such as molecular weight, polar groups, hydrophobicity and high antioxidant activity (Thamnarathip et al., 2016). Also, antioxidant properties depend mainly on the native protein, purification methods, degree of hydrolysis and

\footnotetext{
* Corresponding author.

E-mail address: cmrochainv@gmail.com (C.M.R. Rocha).
} 
conditions, the protease used for the hydrolysis, and amino acid composition of peptides (as basic amino acid (His, Lys) or acidic amino acid residues (Glu, Asp)). In addition, antioxidant activity in hydrolysates from rice bran proteins could be influenced by the phenolic hydroxyl groups of tyrosine, that when they are bonded to the aromatic ring provide atoms that end up the radical chain reaction by scavenging free radicals (Thamnarathip et al., 2016). On the other hand, aromatic ring with hydroxyl groups and carboxylic acid in phenolic compounds have natural interaction that increase their affinity to conjugate with other components (such as lipids, carbohydrates and proteins). These interactions are carried out through hydrogen bonding, covalent bonding, hydrophobic interactions, and ionic bonding, though there are few reports in relation to above. Regarding to proteins, these interactions could lead to changes in functional and biological protein properties (Alu'datt et al., 2016, 2013). Though phenolic compounds are expected to be present in this kind of extracts, the combined analysis of protein and phenolic compounds is rarely considered.

In this context, the aim of this work was to further explore the valorization potential of the protein fraction from RB. This was done by: a) assessing the influence of the extraction protocol in the protein extraction yield and extracts' protein profile; b) fractioning, hydrolyzing and characterizing the different protein fractions and hydrolysate (both by sodium dodecyl sulfate-polyacrylamide gel electrophoresis and highperformance liquid chromatography); c) determination of the total phenolic content (TPC) of each extract, including native and hydrolyzed protein of RB from two different locations (Colombia and Portugal); and d) assessing the bioactivities of protein-based extracts and hydrolysates, in terms of antioxidant and antihypertensive power.

\section{Materials and methods}

\subsection{Raw material and chemicals}

Two different rice bran sources were used in this work: a commercially dried rice bran was purchase from Herdade de Carvalhoso (Ciborro, Portugal); a second sample of rice bran was supplied from a local farm (Tolima, Colombia). All the chemicals were analytical grade and purchased from Sigma-Aldrich Co. (St. Louis, MO).

\subsection{Proximal composition}

The proximal composition of both rice bran was determined in triplicate. The moisture was determined gravimetrically using a moisture analyzer (MAC 50/1/NH, RADWAG, Poland). Total fat content was determined using petroleum ether as solvent, according to the official AOAC method $n^{\circ} 920.39$ with some minor modifications. Protein content in the RB and RBD were determined by the Kjeldahl nitrogen analyzer (Kjeltec ${ }^{\mathrm{TM}} 8400$ Analyzer Unit, Foss) using 5.95 as conversion factor (Amagliani et al., 2017b). Ash and total extractives were determined according to NRLE/TP-510-42622 and NRLE/TP-510-42619 respectively. Total carbohydrate was estimated with the content of nitrogen-free extract using equation (1) (Huang and Lai, 2016). (See Table S1).

Total carbohydrate $(D M, \%)=100-($ crude lipid + crude protein + ash $)$

\subsection{Defatting process of $R B$}

In order to choose the solvent for removed the fat from $\mathrm{RB}$, the methodology described by Wattanasiritham et al. (2016) was selected as base, but several solvent mixtures were tested. Remaining fat, defatting yield and protein loss in the different solvents were also evaluated. Results are shown in supplementary material (Table S2). The solvent selected after the evaluation was ethanol at $96 \%$, without important decrease in the performance of the deffating procedure, thus avoiding the use other organic solvents.

\subsection{Protein extraction from $R B D$}

\subsubsection{Protein solubilization}

Alkaline extraction of protein from RBD was carried out by solubilization/precipitation following the methodology described by Wang et al. (2017) with some modifications. RBD was treated three times with deionized water with a ratio of 1:5 and 1:10 (RBD: water). The solutions were adjusted to $\mathrm{pH} 9$ using $\mathrm{NaOH} 1 \mathrm{M}$ and stirred with a magnetic stirrer at $200 \mathrm{rpm}$ during $2.5 \mathrm{~h}$ at $20{ }^{\circ} \mathrm{C}$, follow by centrifugation at $3000 \times g$ during $10 \mathrm{~min}$. The supernatants' $\mathrm{pH}$ was adjusted to $\mathrm{pH} 4$ to precipitate the proteins and the mixture was centrifuged using the above conditions. After precipitation and recovery by centrifugation, the proteins were re-suspended in deionized water, the $\mathrm{pH}$ was adjusted to 7 , lyophilized and kept at $20^{\circ} \mathrm{C}$ until use.

\subsubsection{Fractionation of proteins from rice bran by the Osborne method}

Fractionation of proteins from RBD was carried out using the methodology described by Chanput et al. (2009), in order to know the protein profile. Four different fractions were obtained: the fraction soluble in water (in principle rich albumin), the fraction soluble in $\mathrm{NaCl}$ (rich in globulin), the fraction soluble in ethanol (rich in prolamin) and the faction soluble in $\mathrm{NaOH}$ (rich in glutelin). For this, $100 \mathrm{~g}$ of RBD was mixed with $500 \mathrm{~mL}$ of deionized water to obtain the albumin fraction. The residue from this step was mixed with $500 \mathrm{~mL}$ of $0.5 \mathrm{M} \mathrm{NaCl}$ to recover the globulin fraction. After the residue was treated with $500 \mathrm{~mL}$ of $70 \%$ ethanol to obtain the prolamin fraction. For last, the residue from prolamin extraction was treated with $\mathrm{NaOH} 0.1 \mathrm{~N}$ to know the content of glutelin. In each step, the extraction was carried out during $1 \mathrm{~h}$ with a magnetic stirrer at $200 \mathrm{rpm}$ and the supernatants were removed by centrifugation at $4000 \times g$ during $30 \mathrm{~min}$. In order to improve the recovery of protein, each extraction step was repeated twice. The albumin, globulin and glutelin fractions were then purified by isoelectric precipitation at $\mathrm{pH} 4.1,4.3$ and 4.8, respectively (Uraipong and Zhao, 2016), and the prolamin was recovery by evaporation of the solvent. After precipitation, the proteins were re-suspended in ultrapure water, the $\mathrm{pH}$ was adjusted to 7 , lyophilized and kept at $20{ }^{\circ} \mathrm{C}$ until use. The protein content and yield of precipitation were calculated as described above.

\subsubsection{Protein recovery}

Protein recovery was measured by the method of Bradford, 1976 and expressed as $\mathrm{g}$ of protein/100 $\mathrm{g}$ of RBD. The protein content was estimated in the supernatant that contain the proteins solubilized (PS), and in the supernatant after isoelectric precipitation (PP).

\subsubsection{Solubility of the extracted proteins}

The purity of the rice bran protein was evaluated in function of the soluble protein and the dry weight. $20 \mathrm{~mL}$ of supernatant before and after isoelectric precipitation were dried at $105^{\circ} \mathrm{C}$ for $5 \mathrm{~h}$. Protein content in the aliquot was measured by the method of Bradford. The solubility was calculated using equation (2) and was expressed as percentage (\%). Measurements were performed at least in duplicate.

Solybility $(\%)=\left(P_{c} V_{a} / W_{s}\right) * 100$

$P_{c}(\mathrm{mg} / \mathrm{mL})$ is the protein concentration in the aliquot, $V_{a}(\mathrm{~mL})$ is the volume of aliquot, $W_{s}(\mathrm{mg})$ is the sample weight.

\subsection{Preparation of rice bran protein hydrolysates (RBPH)}

The protein obtained by the alkaline extraction was re-suspended to $2.5 \%$ in deionized water. $50 \mathrm{~mL}$ of protein solution was hydrolyzed using a ratio 1:100 enzyme-substrate (Zhao et al., 2012). Trypsin type I from bovine pancreas with an activity of 10,000 BAEE units/mg of 
protein was used. The reaction was carried out at $37^{\circ} \mathrm{C}$ and $\mathrm{pH} 8$ during $4 \mathrm{~h} \mathrm{pH}$ was constantly maintained by addition of $\mathrm{NaOH} 0.1 \mathrm{~N}$ using an automatic systems 902 titration equipped with software Tiamo 2.3 (902 Titrando-Metrohm GA, Herisau, Switzerland). The enzyme was inactivated by decreasing the final $\mathrm{pH}$ to 3 .

\subsubsection{Quantification of the hydrolysis degree}

The degree of hydrolysis (DH), defined as the percent ratio of the number of peptide bonds broken (h) to the total numbers of bonds per unit weight $\left(\mathrm{h}_{\mathrm{tot}}\right)$, was determined using the $\mathrm{pH}$-stat method (Alder-Nissen, 1986) and calculated using equation (3) as described by Zhao et al. (2012).

$D H(\%)=\left(\left(B N_{b}\right) /\left(\propto h_{t o t} M_{p}\right)\right) * 100$

Where $B$ and $N_{b}$ are the volume of alkaline solution and its concentration respectively, $h_{\text {tot }}$ is the total number of peptide bonds in the protein substrate $\left(8.4 \mathrm{~m}_{\mathrm{eq}} / \mathrm{g}\right.$ rice bran protein) (Thamnarathip et al., 2016), and $\alpha$ is the average degree of dissociation of the $\alpha-\mathrm{NH}_{2}$ groups and is defined according to equations (4) and (5):

$\propto=10^{p H-p K} /\left(1+10^{p H-p K}\right)$

$p K=7.8+((298-T) /(298 * T)) * 2400$

$\mathrm{pH}$ is the $\mathrm{pH}$ value at which the enzyme hydrolysis was performed and $p K$ is the average dissociation value for the $\alpha$-amino groups liberated during hydrolysis, a parameter depending from hydrolysis temperature.

\subsubsection{SDS-PAGE electrophoresis}

Sodium Dodecyl Sulfate-Polyacrylamide Gel Electrophoresis (SDSPAGE) was conducted to determine the molecular weight distribution of proteins as described by Laemmli (1970). The lyophilized proteins was dissolved in deionized water at $4 \mathrm{mg}$ of protein/mL. Samples were prepared by mixing $16 \mu \mathrm{L}$ of proteins with $4 \mu \mathrm{L}$ of buffer $(0.313 \mathrm{M}$ Tris- $\mathrm{HCl}$ (pH 6.8), $10 \%$ SDS, $50 \%$ of glycerol, $10 \%$ of 2-mercaptoethanol and $0.05 \%$ bromophenol blue), followed by incubation at $100{ }^{\circ} \mathrm{C}$ during $5 \mathrm{~min}$. Then $10 \mu \mathrm{L}$ of mixture was loaded into the gel (4\% acrylamide stacking gel and $12 \%$ acrylamide separating gel). Bands were visualized by staining with protein staining reagent (BlueSafe, nytech ${ }^{\circledR}$ ). The electrophoresis was performed using a semi-dry blot apparatus (Bio-$\mathrm{Rad}$ ), at $30 \mathrm{~mA}$ and $500 \mathrm{~mL}$ of buffer ( $25 \mathrm{mM}$ tris, $192 \mathrm{mM}$ glicin and $0.1 \%(\mathrm{w} / \mathrm{v}) \mathrm{SDS}$ ). The approximate molecular weights were determined using molecular weight (MW) standards ranging from 5 to $250 \mathrm{kDa}$.

\subsubsection{Profile of proteins and hydrolysates}

For the analysis $4 \mathrm{mg}$ of lyophilized protein were diluted in ultrapure water. The profile of the proteins were analyzed by RP-HPLC. Separation was performed on a reversed-phase using a column Hypersil ${ }^{\mathrm{TM}}$ ODS C18 ( $250 \mathrm{~mm} \times 4.6 \mathrm{~mm}, 5 \mu \mathrm{m}$ particle size), operating at $35^{\circ} \mathrm{C}$, installed in a UHPLC chromatograph, equipped with an intelligent HPLC pump LC30AD, NexeraX2, (Shimadzu, Japan). The elution flow rate was $2 \mathrm{~mL} /$ min with the following gradient of HPLC grade solvents (A: $0.1 \%$ trifluoroacetic acid (TFA) in water; B: 0.1\% TFA in acetonitrile): 0-30 min, 0-50\% B; 30-35 min, 50-80\% B; 35-40 min, 80\% B. Monitoring was made at $250 \mathrm{~nm}$ and $35^{\circ} \mathrm{C}$ by diode array detector SPD-M20A, NexeraX2 (Shimadzu, Japan).

\subsection{Phenolic compounds determination}

\subsubsection{Total phenolic content (TPC)}

The TPC was measured by the Folin-Ciocalteu method that was based on the colorimetric reduction/oxidation reaction of phenols (Singleton et al., 1999). For all analyses, $5 \mu \mathrm{L}$ of extract was mixed with $60 \mu \mathrm{L}$ Folin-Ciocalteu reagent, $15 \mu \mathrm{L}$ of $\mathrm{Na}_{2} \mathrm{CO}_{3}(75 \mathrm{~g} / \mathrm{L})$ and $200 \mu \mathrm{L}$ of distilled water. The prepared solution was kept at $60{ }^{\circ} \mathrm{C}$ for $5 \mathrm{~min}$. Absorbance was measured at $700 \mathrm{~nm}$ in a spectrophotometric microplate reader (Synergy HT, BioTek Instruments, Inc., USA). The value was obtained using a standard curve prepared from gallic acid and expressed as milligram gallic acid equivalents (GAE) per gram of sample (mg GAE/g).

\subsubsection{UHPLC analysis of phenolic compounds}

Phenolic compounds of samples were identified using the methodology described by Ferreira-Santos et al. (2019) and analyzed in Shimatzu Nexpera X2 UPLC chromatograph equipped with Diode Array Detector (DAD) (Shimadzu, SPD-M20A). Separation was performed on a reversed-phase Aquity UPLC BEH C18 column $(2.1 \mathrm{~mm} \times 100 \mathrm{~mm}, 1.7$ $\mu \mathrm{m}$ particle size; from Waters) and a pre-column of the same material at $40{ }^{\circ} \mathrm{C}$. The flow rate was set to $0.4 \mathrm{~mL} / \mathrm{min}$. HPLC grade solvents ultra-pure water, formic acid $0.1 \%$ and acetonitrile were used. 23 standard phenolic compounds were tested, but, among these, only 9 were detected. A comparison between the UV spectra (at $250 \mathrm{~nm}$ for ellagic acid; at $280 \mathrm{~nm}$ for p-coumaric and cinnamic acids, naringenin and catechin; at $308 \mathrm{~nm}$ for resveratrol; at $320 \mathrm{~nm}$ for ferulic acid, at $329 \mathrm{~nm}$ for apigenin; at $370 \mathrm{~nm}$ for quercetin) and the retention times of each standard were used to identify and quantify the phenolic acids. Results are expressed as concentration in $\mathrm{mg} / \mathrm{L}$, and analyses were made in triplicate.

\subsection{Determination of antioxidant activity}

\subsubsection{Free radical scavenging activity (DPPH assay)}

The DPPH radical scavenging activity of native protein and protein hydrolysates was determined as described by Ferreira-Santos et al. (2019). The reaction was carried out in a 96-well microplate containing $30 \mu \mathrm{L}$ of sample and $270 \mu \mathrm{l}$ of 2,2-diphenyl-1-picrylhydrazyl solution (DPPH, $10^{-4} \mathrm{M}$, dissolved in methanol to an absorbance value of $0.70 \pm$ 0.01 at $515 \mathrm{~nm}$ ) and allowed to stand for $1 \mathrm{~h}$ in the dark at room temperature. The absorbance was measured at $515 \mathrm{~nm} \mathrm{~nm}$ in a spectrophotometric microplate reader (Synergy HT, BioTek Instruments, Inc., USA). DPPH activity was calculated by using equation (6) and was expressed as $\%$ inhibition.

Inhibition $(\%)=1-(A s / A c) * 100$

Ac and As are the absorbance of the control solution and the absorbance of the sample solution, respectively.

\subsubsection{Radical cation decolorization (ABTS assay)}

The radical cation decolorization (ABTS) assay of native protein and protein hydrolysates was determined as described by Ferreira-Santos et al. (2019). Assays were conducted by combining $10 \mu \mathrm{L}$ of sample with $200 \mu \mathrm{L}$ of ABTS radical cation solution. The resulting solutions were maintained during $30 \mathrm{~min}$ in darkness at room temperature, and the absorbance was then measured at $734 \mathrm{~nm}$ in a spectrophotometric microplate reader (Synergy HT, BioTek Instruments, Inc., USA). The percent inhibition of ABTS radical cation was calculated using equation (6).

\subsubsection{Ferric reducing antioxidant power (FRAP assay)}

FRAP assay was performed according to the methodology described by Meneses et al. (2013). $10 \mu \mathrm{L}$ aliquot of samples was mixed with 290 $\mu \mathrm{L}$ of FRAP reagent and incubated at $37^{\circ} \mathrm{C}$ for 15 min (against a blank that is prepared using a solvent used in the extraction). After that, the absorbance was determined at $593 \mathrm{~nm} \mathrm{~nm}$ in a spectrophotometric microplate reader (Synergy HT, BioTek Instruments, Inc., USA). FRAP values are expressed as micromoles of ferrous equivalent per $\mathrm{g}$ of dry weight material ( $\left.\mu \mathrm{mol} \mathrm{Fe}{ }^{2+} / \mathrm{g} \mathrm{RBD}\right)$.

\subsection{Determination of the angiotensin converting enzyme (ACE) inhibition activity}

ACE-inhibition activity of native protein and protein hydrolysates 
was calculated using the method described by Kumar and Kumar (2017), with some modification. For each assay, $150 \mu \mathrm{L}$ of hippuryl-histidyl-leucine ( $5 \mathrm{mmol} / \mathrm{L}$ Hip-His-Leu in $50 \mathrm{mmol} / \mathrm{L}$ dihydrogen phosphate buffer containing $300 \mathrm{mmol} / \mathrm{L} \mathrm{NaCl}, \mathrm{pH}$ 8.3) was mixed with $135 \mu \mathrm{L}$ of potassium dihydrogen phosphate $500 \mathrm{mmol} / \mathrm{L}$ and $5 \mu \mathrm{L}$ of sample $(1 \mathrm{mg} / \mathrm{mL})$. The reaction was initiated by the addition of $10 \mu \mathrm{L}$ of ACE solution ( $5 \mathrm{mU} / \mathrm{mL}$ ) and incubated at $37^{\circ} \mathrm{C}$ for $60 \mathrm{~min}$. The reaction was stopped by adding of $250 \mu \mathrm{L}$ of $1 \mathrm{~mol} / \mathrm{L} \mathrm{HCl}$ followed by the addition of $1.5 \mathrm{~mL}$ of ethyl acetate and stirring in a vortex during $30 \mathrm{~s}$. The mixture was centrifuged at $400 \times g$ for $20 \mathrm{~min}$ and $1 \mathrm{~mL}$ of the ethyl acetate layer was removed and transferred to a fresh tube. The ethyl acetate was evaporated at $100{ }^{\circ} \mathrm{C}$ during $30 \mathrm{~min}$. The residue containing hippuric acid was dissolved in $1 \mathrm{~mL}$ of deionized water, and the absorbance measured at $228 \mathrm{~nm}$ in a spectrophotometric microplate reader. The degree of ACE inhibition (\%) was calculated according to equation (7) (Pan et al., 2016).

Inhibition of $A C E(\%)=\left(\left(A_{b}-A_{s}\right) /\left(A_{b}-A_{c}\right)\right) * 100$

$A_{b}$ is the absorbance without inhibitor (blank), $A_{s}$ is the absorbance of the reaction mixture (sample), and $A_{c}$ is the absorbance of the control.

\subsection{Statistical analysis}

Statistical significance difference was assessed by ANOVA using Origin Pro 8.1 software. Each analysis was performed at least in duplicate. Differences were reported as significant at $p<0.05$, and the results were expressed as mean \pm standard deviation.

\section{Results and discussion}

\subsection{Proximal composition of rice bran}

The proximal chemical composition of the RB's used in this work is presented and compared to other references in Table S1, as supplementary material.

\subsection{Protein extraction from defatted rice bran}

All results on protein extraction (protein yield and protein recovery) obtained by alkaline extraction of protein from RBD are summarized in Table 1 . The results presented show that the solid-liquid ratio (1:5 and 1:10 RBD:Solvent) did not influence the protein yield and protein recovery in the extraction process. Although the protein precipitation was not complete, during the extraction (step one) around $26 \%$ of the total soluble protein (after precipitation) was recovered (48\%). This means that in just one step it is possible to recovery close to the $56 \%$ of the total protein in the RBD; while in the 1st and 2nd re-extraction the efficiency was lower, with a recovery around $25 \%$ and $19 \%$ of the total soluble protein respectively. These values are equivalent to $12.5 \%$ and $9.5 \%$ of the total protein in RBD. Considering the mass transfers principles, when a system works with a high ratio solvent-solid, the gradient of concentration (as driving force for mass transfer) between the solid and the liquid is higher (Phongthai et al., 2018). However, the high ratio of liquid (1:10) did not improve the process extraction, which suggests that in this case, not significant mass transfer issues occurred with the ratio

Table 1

Effect of the solvent ratio on the protein yield and protein recovery by alkaline extraction and on the proteins extracted by the Osborne method.

\begin{tabular}{|c|c|c|c|c|c|c|}
\hline Ratio RBD:Solvent & $\begin{array}{l}\text { Solubilized protein } \\
(\%)\end{array}$ & $\begin{array}{l}\text { Precipitation yield } \\
(\%)\end{array}$ & $\begin{array}{l}\text { Protein yield } \\
(\%)\end{array}$ & $\begin{array}{l}\text { Protein recovery }(\mathrm{g} / 100 \mathrm{~g} \\
\text { of } \mathrm{RBD})\end{array}$ & $\begin{array}{l}\text { Solubility } \\
(\%)\end{array}$ & $\begin{array}{l}\text { Protein concentration ( } \mathrm{g} \text { of protein/ } \\
100 \mathrm{~g} \text { of extract) }\end{array}$ \\
\hline \multicolumn{7}{|l|}{$1: 5$} \\
\hline Extraction $^{c}$ & $28.61 \pm 0.22$ & $91.56 \pm 0.10$ & $26.19 \pm 0.32$ & $3.97 \pm 0.01$ & $\begin{array}{l}42.82 \pm \\
1.04^{\mathrm{a}}\end{array}$ & \\
\hline 1st Re-extraction & $13.94 \pm 0.07$ & $90.01 \pm 1.13$ & $12.66 \pm 0.09$ & $1.92 \pm 0.00$ & $\begin{array}{l}11.38 \pm \\
0.76^{\mathrm{a}}\end{array}$ & \\
\hline 2nd Re-extraction & $8.90 \pm 1.94$ & $92.60 \pm 0.94$ & $8.56 \pm 0.02$ & $1.45 \pm 0.00$ & $\begin{array}{l}12.98 \pm \\
0.34^{\mathrm{a}}\end{array}$ & \\
\hline $\begin{array}{l}\text { Total protein soluble } \\
1: 10\end{array}$ & & & $47.41 \pm 0.2$ & $7.33 \pm 0.01$ & & $63.20 \pm 1.70$ \\
\hline Extraction & $27.29 \pm 0.53$ & $93.79 \pm 0.11$ & $25.59 \pm 0.50$ & $3.88 \pm 0.10$ & n.q & \\
\hline 1st Re-extraction & $13.93 \pm 1.51$ & $88.65 \pm 1.22$ & $13.00 \pm 0.61$ & $1.97 \pm 0.10$ & n.q & \\
\hline 2nd Re-extraction & $8.83 \pm 2.30$ & $92.73 \pm 3.10$ & $8.92 \pm 0.14$ & $1.50 \pm 0.01$ & n.q & \\
\hline Total protein soluble & & & $47.52 \pm 0.3$ & $7.35 \pm 0.01$ & & \\
\hline \multicolumn{7}{|l|}{ Osborne method } \\
\hline \multicolumn{7}{|l|}{ Albumin } \\
\hline Extraction & $4.51 \pm 0.12$ & $79.40 \pm 0.44$ & $3.58 \pm 0.15$ & $0.54 \pm 0.01$ & n.q & \\
\hline Re-extraction & $2.99 \pm 0.10$ & $84.29 \pm 0.63$ & $2.52 \pm 0.10$ & $0.38 \pm 0.00$ & n.q & \\
\hline Total fraction soluble & & & $6.10 \pm 0.22$ & $0.92 \pm 0.03$ & $\begin{array}{l}43.38 \pm \\
1.84^{\mathrm{b}}\end{array}$ & $42.40 \pm 1.70$ \\
\hline \multicolumn{7}{|l|}{ Globulin } \\
\hline Extraction & $3.64 \pm 0.22$ & $84.04 \pm 0.54$ & $2.81 \pm 0.01$ & $0.38 \pm 0.03$ & n.q & \\
\hline Re-extraction & $1.45 \pm 0.11$ & $91.28 \pm 1.15$ & $1.04 \pm 0.00$ & $0.19 \pm 0.02$ & n.q & \\
\hline Total fraction soluble & & & $3.85 \pm 0.01$ & $0.57 \pm 0.05$ & $\begin{array}{l}41.13 \pm \\
3.77^{\mathrm{b}}\end{array}$ & $41.14 \pm 2.72$ \\
\hline \multicolumn{7}{|l|}{ Prolamin } \\
\hline Extraction & $0.74 \pm 0.01$ & n.q & $0.74 \pm 0.01$ & $0.11 \pm 0.00$ & n.q & \\
\hline Re-extraction & $0.25 \pm 0.00$ & n.q & $0.25 \pm 0.00$ & $0.04 \pm 0.02$ & n.q & \\
\hline Total fraction soluble & & & $1.77 \pm 0.01$ & $0.15 \pm 0.01$ & - & \\
\hline \multicolumn{7}{|l|}{ Glutelin } \\
\hline Extraction & $32.95 \pm 1.22$ & $98.40 \pm 1.25$ & $32.42 \pm 0.81$ & $4.91 \pm 0.12$ & n.q & \\
\hline Re-extraction & $11.42 \pm 0.85$ & $96.83 \pm 0.43$ & $11.06 \pm 0.90$ & $1.67 \pm 0.14$ & n.q & \\
\hline Total fraction soluble & & & $43.47 \pm 1.63$ & $6.59 \pm 0.20$ & $\begin{array}{l}68.96 \pm \\
1.51^{\mathrm{b}}\end{array}$ & $69.01 \pm 1.53$ \\
\hline $\begin{array}{l}\text { Global protein yield of } \\
\text { extraction }\end{array}$ & & & $55.79 \pm 0.73$ & $8.23 \pm 0.11$ & & \\
\hline
\end{tabular}

n.q: not quantified.

a Deionized water-pH 8.

b $\mathrm{NaOH} 0.1 \mathrm{~N}$. RBD: defatted rice bran.

c All values correspond to native protein from Portuguese rice bran. 
1:5. Therefore, it is not necessary to use such higher gradients of concentration to remove the proteins from RBD, and 1:5 is enough. Results are similar to those reported by Inajara et al. (2017). They obtained a protein yield of $45.5 \%$ and $51.1 \%$ by using a ratio RBD: solvent of $1: 7$ and 1:6 respectively, while Phongthai et al. (2018) reported one protein yield of $10.5 \%$ and $10.9 \%$ by using a ratio RBD: solvent of $1.5: 10$ and $2: 10$, respectively. Differences in the protein yield could be explained by the origin and composition of rice bran, the method of defatting and the solid-liquid ratio for the protein extraction.

Table 1 also shows the results of protein fractioning by the Osborne method, including the protein yield and protein recovery for each fraction obtained. The total yield was obtained with the sum of all soluble fractions. Total protein recovery by this method was around to 8.23 $\mathrm{g} / 100 \mathrm{~g}$ of RBD ( $55.8 \%$ of the total protein soluble). The protein yield of the albumin, globulin, prolamin and glutelin fractions was 6.1, 4.5, 1.8 and $43.5 \%$ (from total RBD available protein), respectively. It should be noted that it was not possible to recover and concentrate the protein from the prolamin fraction due to the very low concentration and solvent composition. Therefore, the results presented for this fraction were expressed per $g$ of protein (determined in the liquid phase), instead of per $g$ of extract, whenever applicable.

Solubility of the proteins removed during the first cycle of alkaline extraction $(43 \%)$ presented higher values $(p<0.05)$ than the removed in the 1 st and 2 nd re-extractions, $11 \%$ and $13 \%$ respectively. This could be due to the presence of glutelin (main protein in the RB) and its ability to solubilize at higher $\mathrm{pH}$ (Rafe et al., 2017). This parameter did not present differences between the two re-extraction steps, although significant differences $(p<0.05)$ were detected in the proteins' recovery between the 1st and 2nd re-extraction (see Table 1). On the other hand, the solubility of the fractions rich in albumin and globulin did not present significant differences $(p>0.05)$. However, they presented a higher difference to the solubility of the fraction rich in glutelin, being this ca. $30 \%$ higher. The differences between solubility values can be associates with the affinity of glutelin for alkaline solutions, as previously mentioned. These results are supported by other authors that obtained similar solubility of the RB protein using enzymatic extraction (Rafe et al., 2017; Zhao et al., 2012).

\subsection{Characterization of RB proteins and hydrolysates}

\subsubsection{Degree of protein hydrolysis $(\mathrm{DH})$}

The corresponding proteins recovered by alkaline extraction were combined (called from now on native protein). and hydrolyzed. The degree of enzymatic hydrolysis of RBP with trypsin $\left(\mathrm{pH} 8,37^{\circ} \mathrm{C} \mathrm{E} / \mathrm{S}=\right.$ 1:100) is shown in Fig. 1. The hydrolysis proceeded rapidly during the initial $40 \mathrm{~min}$, which indicate that the maximum cleavage of peptides occurred during this time (Zhao et al., 2012), as expected. Similar behavior was found for the hydrolysis of other proteins, such as whey protein isolated with trypsin (Rocha et al., 2011). Protein from rice bran is rich in amino acid such as valine, tyrosine, leucine, histidine, lysine, isoleucine, and arginine among others (Liu et al., 2017). Some authors have reported a content of amino acid in rice bran protein between 2.99 and $5.4(\mathrm{~g} / 100 \mathrm{~g}$ dry mater) and 7.81-10.2 (g/100 g dry mater) for lysine and arginine, respectively (Amagliani et al., 2017a, 2017b). Glutelin has a higher Lys and Arg amino acid concentration: 2.5-4.5 and 9.0-10 g/16.8 g nitrogen, respectively (Amagliani et al., 2017b). Taking this into account and that the hydrolyzed protein could be rich in glutelin, these factors could encourage the hydrolysis with trypsin because it has a preferential release of $\mathrm{N}$-terminal from Arg and Lys (Tavano, 2013). As the reaction proceeds, fewer and fewer peptide bonds are available per unit of enzyme, and this causes the decrease in the reaction rate (see Fig. 1). Furthermore, other explanations may apply such as substrate saturation or peptide inhibition. RB protein hydrolysis from trypsin (DH, 5.8\%) was similar to those reported by Thamnarathip et al. (2016) for RB proteins using Flavourzyme (DH, 5.6\%) and to those reported by Yang et al. (2007) for hydrolysis of corn protein with trypsin

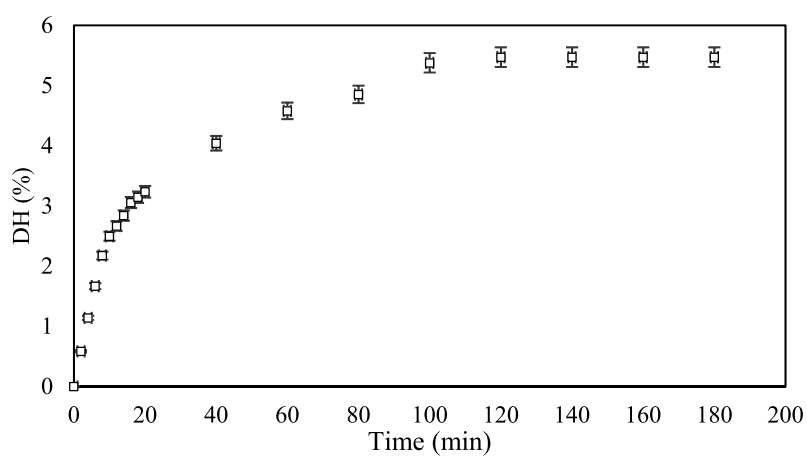

Fig. 1. Degree of enzymatic hydrolysis of rice bran protein (RBP) with trypsin at $\mathrm{pH} 8,37^{\circ} \mathrm{C}$, ratio enzyme/substrate $(\mathrm{E} / \mathrm{S})=1: 100$.

(DH, 8.97\%). However, the hydrolysis can reach higher DH when using a proteolytic cocktail or less specific enzymes, as trypsin breaks mainly at Arg and Lys amino acids. Uraipong and Zhao (2016) reached values up to $30 \%$, with purified rice proteins hydrolysates by Protamax. However, this was a purified protein extract and less pure extracts may contain inhibitory compounds. For instance, the low yield of hydrolysis here reported could be due to the presence of compounds as fiber and phytate, which are very difficult to remove from RB because they are strongly bounded to proteins (Amagliani et al., 2017a).

\subsubsection{Gel electrophoresis}

The electrophoretic profiles of the RB proteins recovered by alkaline extraction, protein fractions obtained with the Osborn method, native protein and RBPH are shown in Fig. 2. Proteins from alkaline extraction (Fig. 2A, lane 2), presented bands of molecular weigh between 10 and $60 \mathrm{kDa}$; bands from 1st re-extraction (Fig. 2A lane 3) and 2nd reextraction (Fig. 2A lane 4) were more intense (18-20 kDa) and relatively intense between $<10$ and $18 \mathrm{kDa}$ and $20-50 \mathrm{kDa}$. These differences in the molecular weight may be caused by the recycles of extraction and the high time of exposure in alkaline solutions, which could partially hydrolyze the proteins affecting its molecular weight. Depending on the intended protein application, this may have to be considered when designing the extraction protocol, as it may alter proteins functionality. The fraction rich in albumin (Fig. 2B lane 2) presented a wide molecular weight $8-12 \mathrm{kDa}, 16-18 \mathrm{kDa}$ and $22-25$ $\mathrm{kDa}$, and presented intense bands between 35 and $38 \mathrm{kDa}$, and $50-70$ $\mathrm{kDa}$. The fraction rich in glutelin (Fig. 2B lane 3) presented bands with very low intensity in ranges $<20 \mathrm{kDa}$ and $40-50 \mathrm{kDa}$. In the case of the fractions rich in globulin and prolamin (Fig. 3 B lane 5 and lane 6 respectively), globulin presented a remarked band in a range of 55-60 $\mathrm{kDa}$ while prolamin presented small molecular weight $<10 \mathrm{kDa}$; this could be because of this protein fraction was not purified by isoelectric precipitation and the proteins were present in very low concentrations when compared to the other fractions and with higher relative amounts of contaminants. Similar results from RB proteins fractions electrophoretic characterization have been reported by Amagliani et al. (2017a). Furthermore, the electrophoretic profile for the native protein (Fig. $2 \mathrm{C}$ lane 1) shows relatively intense bands in the range of $28-50 \mathrm{kDa}$, and very intense bands in the range $<20 \mathrm{kDa}$. On the other side, $\mathrm{RBPH}$ just present intense bands for molecular weight $<20 \mathrm{kDa}$. These differences confirm that the hydrolysis of the proteins occurred, resulting in the breaking of peptidic bonds and significantly reducing the molecular weight.

\subsubsection{Protein profile}

Chromatograms of the RB proteins recovered by alkaline extraction and protein fractions obtained with the Osborn method, are presented in Fig. 3A and B respectively. The profile of the protein obtained by alkaline extraction presented peaks with an average retention time between 


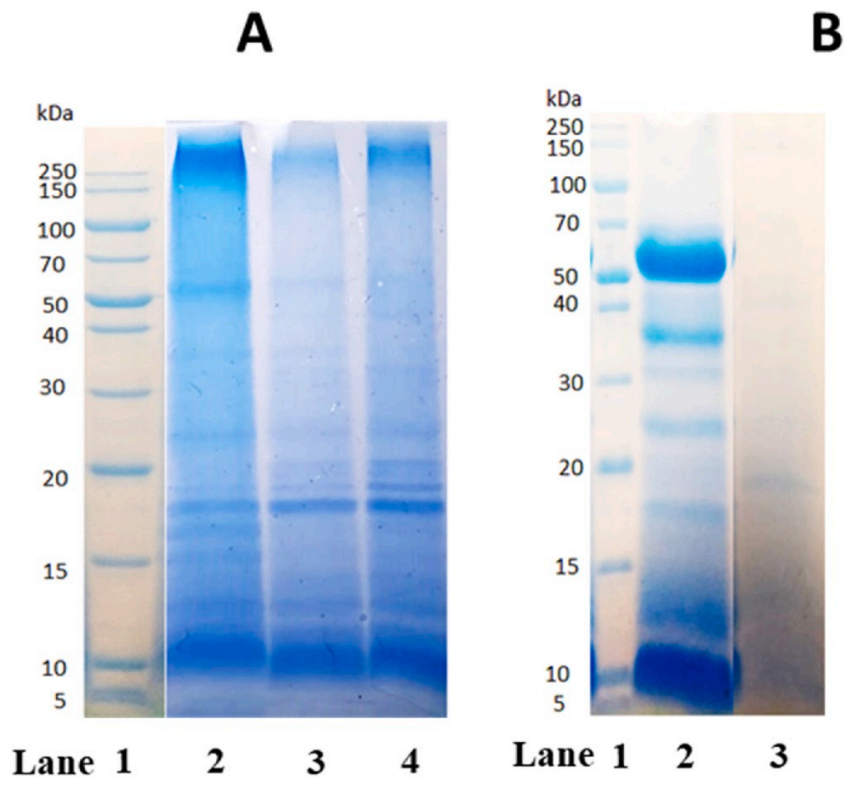

B

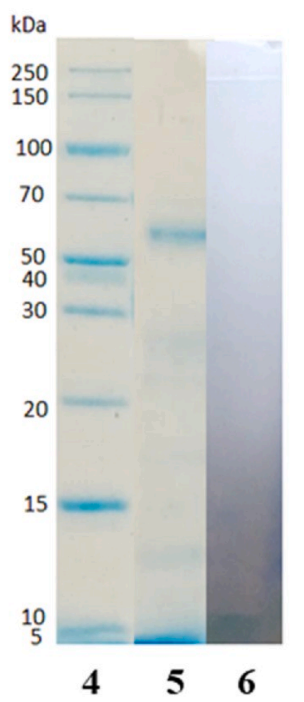

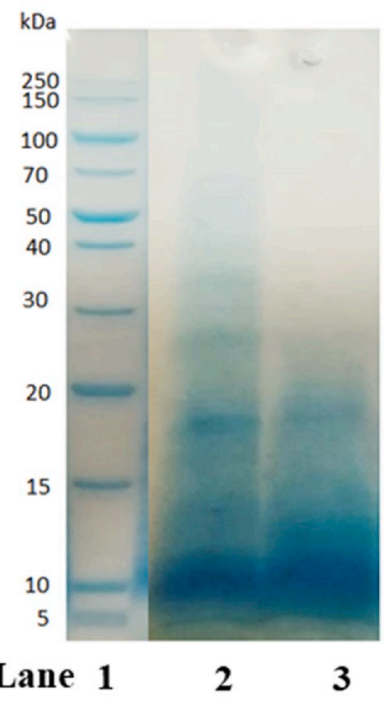

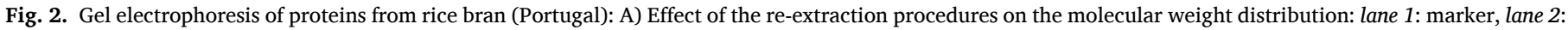

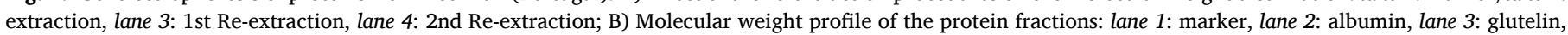

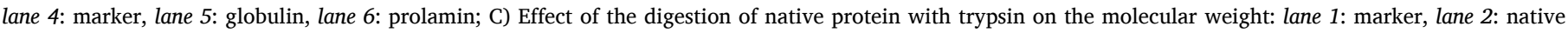
protein, line 3: rice bran protein hydrolysate (RBPH).

7 and $12 \mathrm{~min}$, with the presence of a peak at $20 \mathrm{~min}$; this last peak is smaller for the 1st re-extraction and it is absent in the 2 nd re-extraction. The higher retention time of this peak probably corresponds to a protein with higher molecular weight (usually with higher hydrophobicity and therefore with a higher retention time in reversed-phase chromatography), confirming the results observed in the gel electrophoresis (Fig. 2A). In fact, the intense band present at around $50 \mathrm{kDa}$ in the lane 2 (extraction) is not present in the lane 3 and 4, indicating a content of proteins with higher molecular weight for the extraction than for the two re-extractions. The presence of peaks with retentions time of 6-12 min and 5-11 min can also be observed in the chromatograms, for the fraction rich in albumin and globulin, respectively. The fraction rich in glutelin presented a wide range of retention times, with peaks more representatives between 8-15 $\mathrm{min}$ and $20-22 \mathrm{~min}$, and less representatives between 5 and $7 \mathrm{~min}$. The presence of a major peak for the fraction rich in glutelin (retention time 21-22 $\mathrm{min}$ ) could be due to a protein with high molecular weight (60 kDa) (see Fig. 2B lane 5). Prolamin was the fraction that presented peaks with the lowest area (in accordance with the lowest protein recovery, but mainly due to the absence of the recovery step by isoelectric precipitation), with one representative peak with a retention time of $\approx 11 \mathrm{~min}$ and two minor peaks at $18 \mathrm{~min}$ and $20-21 \mathrm{~min}$. Profile RP-HPLC for protein recovered by alkaline extraction and for the fractions obtained by the Osborn method have not been reported previously. The profile of native protein and protein hydrolysate are shown in Fig. 3C. These two profiles are significantly different. Though both present peaks between 3 and 5 min and between 7.5 and $12.5 \mathrm{~min}$ and a major peak around $6.2 \mathrm{~min}$, the area of the peaks below $5 \mathrm{~min}$ is significantly higher for the protein hydrolysate, indicating lower molecular weight proteins confirming the hydrolysis. These peaks for protein hydrolysates are related with appearance of small peptides formed during the trypsin digestion, corresponding to a DH of 5.8\%, also showed in the electrophoresis (Fig. 2C lane 3 and lane 4). Furthermore, the peaks at $7.6 \mathrm{~min}$ and between 8.5 and $9.5 \mathrm{~min}$ are also bigger for the hydrolysis in comparison to the native protein. These peaks can come from the hydrolysis of the proteins with elution time between 11.5 and 12.5 , which seems to be present in a higher amount in the native protein.

\subsection{Total content and individual identification/quantification of phenolic compounds}

Table 2 shows the approximate phenolic content values of the RB samples. The TPC of the alkaline protein extraction (native protein) of RB from Portugal, was approximately $25.3 \pm 0.3 \mathrm{mg} \mathrm{GAE} / \mathrm{g}$ RBD, and during trypsin digestion free phenolic compounds can be released, observing a significant increase $(p<0.05)$ in the total phenolic content resulting from the enzymatic hydrolysis ( $27 \pm 2 \mathrm{mg}$ GAE/g RDB). Although the concentration of TPC in RB from Colombia was lower than $\mathrm{RB}$ from Portugal, it also had a significant increase after trypsin digestion, going from $12.6 \pm 0.1$ to $14.4 \pm 0.1 \mathrm{mg} \mathrm{GAE} / \mathrm{g}$ RBD.

Previously, Thamnarathip et al. (2016) reported that when rice bran is hydrolyzed with Flavourzyme an increase of phenolic and peptide compounds with phenolic groups is achieved. In the case of the fractions obtained by Osborn method (see Table 2), the highest amounts of TPC were found in the glutelin protein fraction ( $46.4 \pm 1 \mathrm{mg} \mathrm{GAE} / \mathrm{g}$ sample), followed by the prolamin, albumin and globulin rich fractions, respectively $(1.6 \pm 0,1.5 \pm 0$ and $0.9 \pm 0 \mathrm{mg} \mathrm{GAE} / \mathrm{g}$ sample). These results were expected when analysing the different solvents in each step and method of extraction. It is known that the use of ethanol provides a higher extraction of phenolic compounds from various plants including rice bran (Huang and Lai, 2016). However, the highest content of TPC in glutelin (soluble in alkali), can also be compared with the TPC in the native protein (achieved by alkaline extraction), confirming that the native protein is mainly composed by glutelin.

These values should be interpreted with caution as proteins, and other compounds with antioxidant activity (such as the peptides formed through enzymatic hydrolysis) are likely to interfere with the measure (Everette et al., 2010). In this sense, in complex mixtures as these, TPC can be seen as another measure of the overall antioxidant ability. The content in phenolic compounds should be confirmed by other complementary methods. In the present case, UPLC was used and the results are discussed below.

UHPLC analysis was used to identify and quantify phenolic compounds in the native protein, hydrolyzed protein from RB (from Portugal and Colombia) and in the fractions obtained by Osborn fractioning method, by comparison with standard compounds. The results are summarized in Table 3. In the native protein (Portugal and Colombia) it 
A

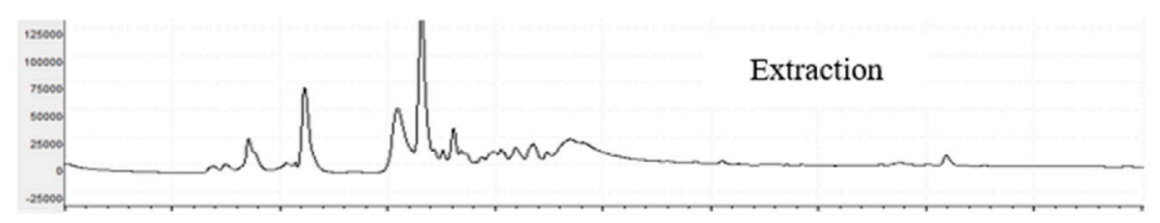

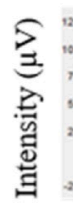
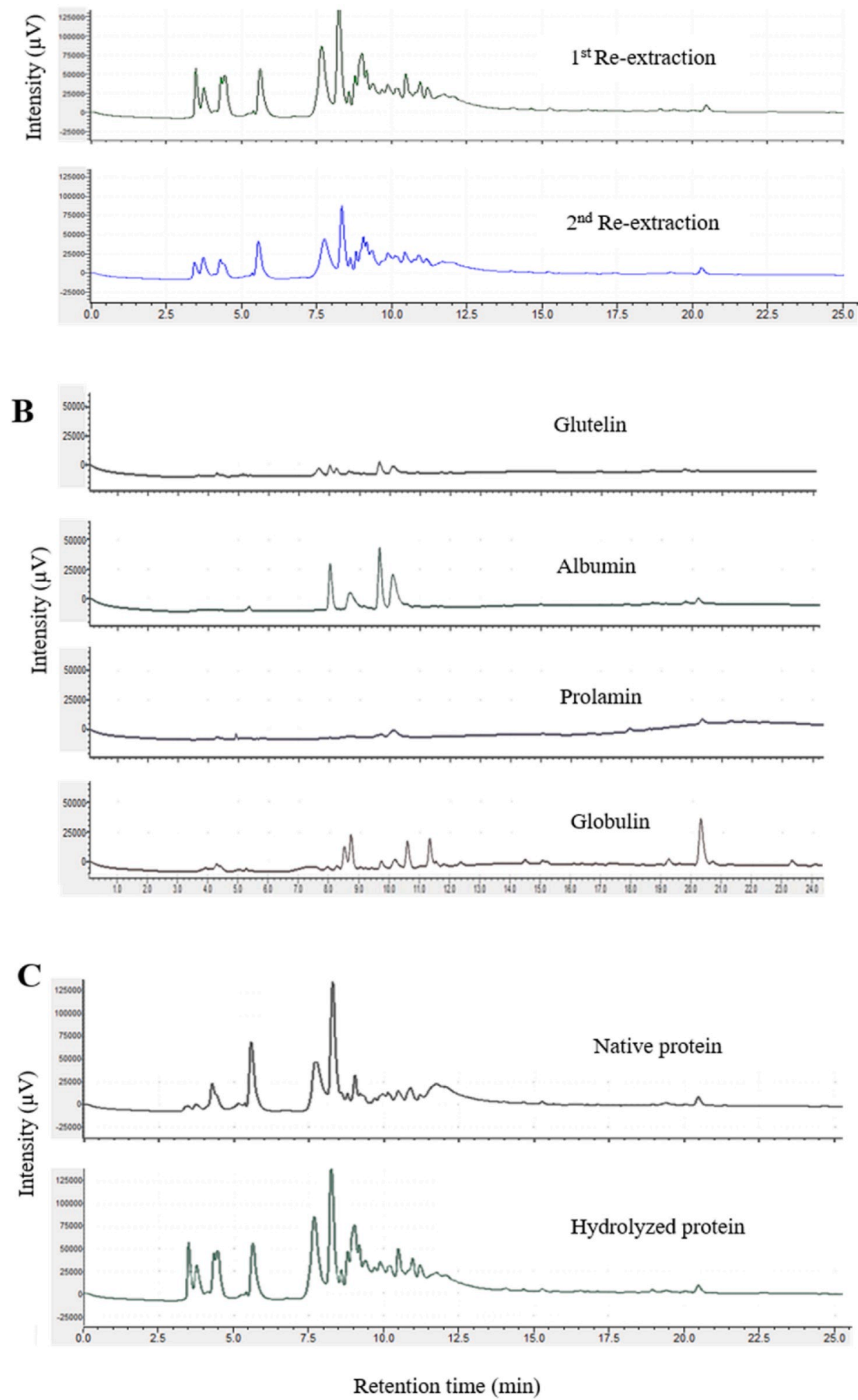

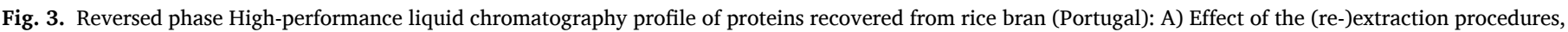
B) Osborn protein fractions, C) Hydrolysis with trypsin. 
Table 2

Antioxidant activities and total phenolic content of rice bran protein hydrolysates (RBPH) and protein fraction.

\begin{tabular}{|c|c|c|c|c|c|c|}
\hline \multirow[t]{2}{*}{ Sample } & ABTS & DPPH & FRAP & ACE & TPC & TPC \\
\hline & \multicolumn{2}{|l|}{ Inhibition (\%) } & $\left(\mu \mathrm{mol} \mathrm{Fe} \mathrm{ec}^{2 \mathrm{c}} /\right.$ of protein) & Inhibition (\%) & (mg GAE/g of RBD) & (mg GAE/g of extract) \\
\hline Native Protein ${ }^{\mathrm{a}}$ & $82.2 \pm 0.7$ & $56.4 \pm 1.5$ & $1266 \pm 36$ & $45.4 \pm 0.4$ & $25.3 \pm 0.3$ & $218 \pm 2$ \\
\hline Protein Hydrolyzed $^{\mathrm{a}}$ & 100 & $68.9 \pm 0.2$ & $1700 \pm 20$ & $67.0 \pm 1.1$ & $27.3 \pm 0.8$ & $236 \pm 7$ \\
\hline Native Protein ${ }^{\mathrm{b}}$ & $21.1 \pm 1.4$ & $13.5 \pm 0.4$ & $711 \pm 13$ & n.d & $12.6 \pm 0.1$ & $70 \pm 1$ \\
\hline Protein Hydrolyzed ${ }^{\mathrm{b}}$ & $39.1 \pm 0.3$ & $22.3 \pm 0.8$ & $862 \pm 28$ & n.d & $14.4 \pm 0.1$ & $80 \pm 1$ \\
\hline \multicolumn{7}{|l|}{ Protein fraction } \\
\hline Albumin & $21.2 \pm 0.5$ & $17.7 \pm 0.6$ & $671 \pm 18$ & n.q & $1.47 \pm 0.01$ & $68.0 \pm 0.2$ \\
\hline Globulin & $26.4 \pm 0.1$ & $20.8 \pm 0.3$ & $669 \pm 15$ & n.q & $0.92 \pm 0.01$ & $66.6 \pm 0.6$ \\
\hline Prolamin & 100 & $81.9 \pm 7.1$ & $9696 \pm 80$ & n.q & $1.56 \pm 0.08$ & $1042 \pm 51^{c}$ \\
\hline Glutelin & 100 & $66.5 \pm 7.3$ & $7375 \pm 12$ & n.q & $46.4 \pm 0.7$ & $486 \pm 7$ \\
\hline
\end{tabular}

ABTS: radical cation decolorization, DPPH: free radical scavenging activity, FRAP: ferric reducing antioxidant power, ACE: angiotensin converting enzyme, TPC: total phenolic compounds. Sample concentrations (ABST and DPPH): $1 \mathrm{mg} / \mathrm{mL}$ for native and hydrolyzed protein, $0.2 \mathrm{mg} / \mathrm{mL}$ for protein fractions.

n.d: not detected and n.q: not quantified.

a Rice bran from Portugal.

b Rice bran from Colombia.

c It was not possible to recover this fraction by isoelectric precipitation; the results of prolamin are presented in mg/g protein.

was possible to identify three major compounds (ferulic, ellagic and cinnamic acids). The contents in ferulic, cinnamic and ellagic acids in the extracts of RB from Portugal were ca. $40 \%$ higher than in the native protein of RB from Colombia (respectively) $(p<0.05)$.

For the trypsin hydrolysates samples it is possible to identify one more phenolic acid, the $p$-coumaric. In addition, a significant increase of the ellagic acid content was observed in both hydrolyzed samples, and ferulic acid for Colombian RB samples, $(p<0.05)$. These phenolic compounds were probably entrapped in or bounded to the protein quaternary structure and were released by the protein hydrolysis. Apparently, the content of cinnamic acid was not affected by trypsin digestion. These overall increase in the phenolic compounds by protein hydrolysis correlates well with the differences in the studied bioactivities between both samples and respective hydrolysates.

For the fractions obtained by the Osborn method, the results of liquid chromatography confirm the results of TPC, showing the presence of more phenolic compounds in the fractions obtained by alkaline (glutelin) and ethanol (prolamin) extraction compared to the fractions rich in albumin and globulin. As can be seen in Table 3, the fraction rich in albumin only shows ferulic and cinnamic acid, resveratrol and naringenin; the globulin-rich fraction has, in addition to these, p-coumaric and ellagic acid. Interestingly, the fractions rich in prolamin and glutelin also have some more flavonoids. In the case of the prolamin-rich fraction, direct comparisons are difficult as the isoelectric precipitation of the protein was not possible, and this fraction was not purified. In spite of this, it is clear that this fraction has more diverse phenolic compounds, including more flavonoids, such as quercetin and apigenin. This was expectable as $70 \%$ ethanol is frequently described as a good solvent for phenolic compounds. Furthermore, the alkaline conditions applied to obtain the glutelin fraction are usually also associated with the solubilization of lignin thus freeing more phenolic monomers. This resulted in the additional presence of catechin, together with the quercetin and apigenin that were already present in the prolamin fraction. In addition, an increased content in naringenin was also detected in these two fractions. Interestingly, only phenolic acids were detected in the native and hydrolyzed fractions, indicating that the longer alkaline treatment degraded more complex phenolic compounds.

Our study is in agreement with that reported by Wanyo et al. (2014) they found that ferulic acid was the most predominant phenolic acid in samples of rice bran from Thailand. Another study by Wu et al. (2018) also demonstrated that ferulic and $p$-coumaric acids were the phenolics present in higher concentration in RB samples.

\subsection{Potential bioactivities assessment}

The antioxidant activity (FRAP, ABTS and DPPH) and antihypertensive (ACE) properties of RB samples from alkaline extraction (native protein) and hydrolyzed protein are presented in Table 2 . The results of

Table 3

Phenolic composition of native protein, protein hydrolyzed and protein fractions by UHPLC-DAD.

\begin{tabular}{|c|c|c|c|c|c|c|c|c|c|}
\hline $\begin{array}{l}\text { Phenolic Compound (mg/g of } \\
\text { extract) }\end{array}$ & Ferulic acid & $\begin{array}{l}p \text {-coumaric } \\
\text { acid }\end{array}$ & Ellagic acid & $\begin{array}{l}\text { Cinnamic } \\
\text { acid }\end{array}$ & Catechin & Quercetin & Resveratrol & Naringenin & Apigenin \\
\hline Native Protein ${ }^{a}$ & $\begin{array}{l}13.03 \pm \\
0.10\end{array}$ & n.d & $7.25 \pm 0.38$ & $3.42 \pm 0.25$ & n.d & n.d & n.d & n.d & n.d \\
\hline Protein Hydrolyzed ${ }^{\mathrm{a}}$ & $\begin{array}{l}13.19 \pm \\
0.50\end{array}$ & $12.93 \pm 0.25$ & $8.72 \pm 0.13$ & $3.42 \pm 0.63$ & n.d & n.d & n.d & n.d & n.d \\
\hline Native Protein ${ }^{\mathrm{b}}$ & $7.88 \pm 0.10$ & n.d & $4.77 \pm 0.08$ & $1.91 \pm 0.16$ & n.d & n.d & n.d & n.d & n.d \\
\hline Protein Hydrolyzed ${ }^{b}$ & $8.21 \pm 0.08$ & $7.54 \pm 0.24$ & $5.39 \pm 0.16$ & $1.91 \pm 0.08$ & n.d & n.d & n.d & n.d & n.d \\
\hline \multicolumn{10}{|l|}{ Protein fraction } \\
\hline Albumin & $\begin{array}{l}27.73 \pm \\
0.60\end{array}$ & n.d & n.d & $8.42 \pm 0.14$ & n.d & n.d & $\begin{array}{l}28.61 \pm \\
0.60\end{array}$ & $3.54 \pm 0.60$ & n.d \\
\hline Globulin & $\begin{array}{l}24.74 \pm \\
0.29\end{array}$ & $8.98 \pm 0.10$ & $\begin{array}{l}13.82 \pm \\
0.24\end{array}$ & $8.16 \pm 0.32$ & n.d & n.d & $\begin{array}{l}28.58 \pm \\
0.29\end{array}$ & $4.20 \pm 0.88$ & n.d \\
\hline Prolamin ${ }^{c}$ & $\begin{array}{l}70.19 \pm \\
0.71\end{array}$ & $48.69 \pm 1.01$ & $\begin{array}{l}38.56 \pm \\
1.01\end{array}$ & $34.77 \pm 1.09$ & n.q & $\begin{array}{l}36.48 \pm \\
4.04\end{array}$ & $\begin{array}{l}73.52 \pm \\
6.56\end{array}$ & $108.0 \pm 5.0$ & $\begin{array}{l}17.92 \pm \\
1.14\end{array}$ \\
\hline Glutelin & $\begin{array}{l}77.79 \pm \\
2.46\end{array}$ & $19.07 \pm 0.40$ & $\begin{array}{l}24.34 \pm \\
1.73\end{array}$ & $13.99 \pm 0.94$ & $\begin{array}{l}47.89 \pm \\
1.97\end{array}$ & $\begin{array}{l}23.20 \pm \\
1.01\end{array}$ & $\begin{array}{l}57.20 \pm \\
3.24\end{array}$ & $\begin{array}{l}30.74 \pm \\
2.46\end{array}$ & $\begin{array}{l}34.53 \pm \\
4.43\end{array}$ \\
\hline
\end{tabular}

n.d: not detected.

${ }^{\text {a }}$ Rice bran from Portugal.

b Rice bran from Colombia.

c It was not possible to recover this fraction by isoelectric precipitation; the results of prolamin are presented in mg/g protein. 
antioxidant activity determined by radical scavenging activities (DPPH and ABTS) and reducing antioxidant power (FRAP) show that RB protein hydrolyzed by trypsin presented significantly higher activities $(p<$ 0.05 ) than that of native protein obtained by alkaline extraction for both studied samples (Portugal and Colombia). The relative amounts of antioxidant activity inhibition when the proteic-phenolic samples were subjected to trypsin hydrolysis was approximately 39 and $100 \%$ in the ABTS assay, 22 and $69 \%$ in the DPPH for RB from Colombia and Portugal, respectively. For FRAP assay the antioxidant reducting power represent a $1700 \mu \mathrm{mol} \mathrm{Fe} \mathrm{Fe}^{2+} / \mathrm{g}$ sample for RB from Portugal and 862 $\mu \mathrm{mol} \mathrm{Fe}^{2+} / \mathrm{g}$ sample for RB from Colombia. As the increase in the phenolic compounds' content with the hydrolysis was very low for the $\mathrm{RB}$ protein from Colombia, these results indicate that the increase in the antioxidant activity in this case is related with the amino acid residues in the peptides formed during the digestion with trypsin. Albeit this, the ABTS radical-scavenging capacity assay and DPPH radical scavenging assay in the protein hydrolyzed (100 and $68.92 \%$, respectively) of RB from Portugal was better that the RB from Colombia, indicating that phenolic compounds have also an important role. In this work, the native and hydrolyzed protein from the Portuguese RB presented the highest concentrations of TPC (see Table 2), which could be associated with the higher antioxidant properties. In fact, phenolic compounds may affect biological properties of the proteins (Alu'datt et al., 2013). It is known that aromatic ring with hydroxyl groups and carboxylic acid in phenolic compounds have natural interaction that increase their affinity to conjugate with other compounds (e.g. proteins). Regarding to protein hydrolysates, these interactions could lead to increase antioxidant properties due to the fragmentation of the protein, allowing either stronger interaction with the phenolic compounds present in the resultant protein fractions or the effective releasing the phenolic compounds. In this sense, our results show that the presence of phenolic compounds and their interaction with proteins/peptides leads to an increase in antioxidant activity, especially in hydrolysates where the concentration of phenolic compounds is higher (see Table 2).

One extra factor to consider in this work is that the RB protein concentrates obtained were not purified, and could present other compounds such as carbohydrates and lipids, that when they are associated with phenolic compounds may impair antioxidant properties. Furthermore, the presence of phytic acid affect the antioxidant activity too (Alu'datt et al., 2013). Therefore, bioactive features of these RB protein concentrates could be further improved.

In addition, the antihypertensive activity determined by the inhibition of ACE, mechanism involved in the antihypertension, showed that the RB protein digested by trypsin provided the highest ACE inhibitory percentage values (67\%) comparing with native protein activity (45\%) $(p<0.05)$. Our results indicate that trypsin disrupt protein-phenolic complexes releasing more phenolic compounds and peptides with phenol groups, resulting in higher antioxidant and hypertensive activities.

These results are supported by other researchers demonstrating that protein hydrolysates of the RB have a high antioxidant (Phongthai et al., 2018; Thamnarathip et al., 2016) and antihypertensive activities (Uraipong and Zhao, 2016; Yang et al., 2007).

Moreover, when the Osborne method was used to obtain the different protein fractions (Table 2), it was observed that the fractions rich in prolamin and glutelin had a much higher antioxidant activity than total (native) protein and fractions rich in albumin and globulin $(p$ $<0.05$ ). However, in the ABTS assay the prolamin and glutelin fraction showed $100 \%$ inhibition of the radicals while the albumin and globulin fraction only inhibited $21 \%$ and $26 \%$, respectively. When the antioxidant activity is determined by the DPPH and FRAP method it was observed that the prolamin rich fraction demonstrated higher antioxidant activity followed by glutelin (see Table 2). These results may have to do with the high amount of phenols present in these two fractions, increasing their biological activity, as previously mentioned.

\section{Conclusions}

This study showed an efficient extraction of proteins from RB, in order to allow their valorization. Ethanol could replace other organic solvents in the defatting process, without significant losses of protein.

The presence of phenolic compounds in the protein fractions leads to an increase in the activity of the protein extracts, representing a synergistic effect between the protein and the RB phenolic compounds. Though the protein concentrates had already a significant bioactivity, protein hydrolysates showed that different antioxidant activities and ACE inhibitory activity significantly increased with the protein digestion by trypsin. RB protein hydrolysis can be used to increase the industrial potential of valorization, both by increasing the protein digestibility and by providing bioactive features, with application in food formulations, cosmetics and pharmaceuticals.

\section{Ethical approval}

This article does not contain any studies with human participants or animals performed by any of the authors.

\section{Declaration of competing interest}

The authors declare that they have no known competing financial interests or personal relationships that could have appeared to influence the work reported in this paper.

\section{CRediT authorship contribution statement}

Y.A. Rodríguez-Restrepo: Conceptualization, Methodology, Investigation, Formal analysis, Data curation, Writing - original draft, Writing - review \& editing. P. Ferreira-Santos: Methodology, Investigation, Formal analysis, Data curation, Writing - review \& editing. C.E. Orrego: Conceptualization, Supervision, Writing - review \& editing, Funding acquisition. J.A. Teixeira: Conceptualization, Writing - review \& editing, Resources, Supervision, Funding acquisition. C.M.R. Rocha: Conceptualization, Methodology, Resources, Formal analysis, Writing review \& editing, Supervision, Funding acquisition.

\section{Acknowledgments}

The authors acknowledge the financial support of the National University of Colombia, call to International Mobility 2017-2018, COLCIENCIAS call 727 National Doctorates, the Erasmus+Programme Key Action 1, the Portuguese Foundation for Science and Technology FCT under the scope of the strategic funding of UID/BIO/04469/2019 unit, the European Regional Development Fund and the European Social Fund under the scope of Norte 2020 - Programa Operacional Regional do Norte (BioTecNorte operation - NORTE-01-0145-FEDER-000004 and doctoral advanced training call NORTE-69-2015-15 - ref. NORTE-085369-FSE-000036).

\section{Appendix A. Supplementary data}

Supplementary data to this article can be found online at https://doi. org/10.1016/j.jcs.2020.103039.

\section{References}

Alder-Nissen, J., 1986. Enzymic Hydrolysis of Food Proteins. Elsevier Applied Science Publisher, New York.

Alu'datt, M.H., Rababah, T., Alhamad, M.N., Gammoh, S., Ereifej, K., Kubow, S., Alli, I., 2016. Characterization and antioxidant activities of phenolic interactions identified in byproducts of soybean and flaxseed protein isolation. Food Hydrocolloids 61, 119-127.

Alu'datt, M.H., Rababah, T., Ereifej, K., Brewer, S., Alli, I., 2013. Phenolic-protein interactions in oilseed protein isolates. Food Res. Int. 52, 178-184. 
Amagliani, L., O'Regan, J., Kelly, A.L., O'Mahony, J.A., 2017a. Composition and protein profile analysis of rice protein ingredients. J. Food Compos. Anal. 59, 18-26.

Amagliani, L., O'Regan, J., Kelly, A.L., O'Mahony, J.A., 2017b. The composition, extraction, functionality and applications of rice proteins: a review. Trends Food Sci. Technol. 64, 1-12.

Bradford, M., 1976. Rapid and sensitive method for quantification of microgram quantities of protein utilizing principle of protein-dye-binding. Anal. Biochem. 248-254.

Chanput, W., Theerakulkait, C., Nakai, S., 2009. Antioxidative properties of partially purified barley hordein, rice bran protein fractions and their hydrolysates. J. Cereal. Sci. 49, 422-428.

Everette, J.D., Bryant, Q.M., Green, A.M., Abbey, Y.A., Wangila, G.W., Walker, R.B., 2010. Thorough study of reactivity of various compound classes toward the folinCiocalteu reagent. J. Agric. Food Chem. 58, 8139-8144.

Ferreira-Santos, P., Genisheva, Z., Pereira, R.N., Teixeira, J.A., Rocha, C.M.R., 2019. Moderate electric fields as a potential tool for sustainable recovery of phenolic compounds from Pinus pinaster bark. ACS Sustain. Chem. Eng. 7, 8816-8826.

Huang, Y., Lai, H., 2016. Bioactive compounds and antioxidative activity of colored rice bran. J. Food Drug Anal. 4, 564-574.

Inajara, B., Piotrowicz, B., Salas-Mellado, M.M., 2017. Protein concentrates from defatted rice bran: preparation and characterization. Food Sci. Techology 37, 165-172.

Kaewka, K., Therakulkait, C., Cadwallader, K.R., 2009. Effect of preparation conditions on composition and sensory aroma characteristics of acid hydrolyzed rice bran protein concentrate. J. Cereal. Sci. 50, 56-60.

Kumar, R., Kumar, V., 2017. Effect of germination on antioxidant and ACE inhibitory activities of legumes. LWT - Food Sci. Technol. (Lebensmittel-Wissenschaft -Technol.) 75, 51-58.

Laemmli, U., 1970. Cleavage of structural proteins during the assembly of the head of bacteriophage T4. Nature 227, 680.

Liu, K. lun, Zheng, J., bao, Chen, sheng, F., 2017. Relationships between degree of milling and loss of Vitamin B, minerals, and change in amino acid composition of brown rice. LWT - Food Sci. Technol. (Lebensmittel-Wissenschaft -Technol.) 82, 429-436.

Meneses, N.G.T., Martins, S., Teixeira, J.A., Mussatto, S.I., 2013. Influence of extraction solvents on the recovery of antioxidant phenolic compounds from brewer's spent grains. Separ. Purif. Technol. 108, 152-158.

Pan, S., Wang, S., Jing, L., Yao, D., 2016. Purification and characterisation of a novel angiotensin-I converting enzyme (ACE)-inhibitory peptide derived from the enzymatic hydrolysate of Enteromorpha clathrata protein. Food Chem. 211, 423-430.
Phongthai, S., Amico, S.D., Schoenlechner, R., Homthawornchoo, W., Rawdkuen, S., 2018. Fractionation and antioxidant properties of rice bran protein hydrolysates stimulated by in vitro gastrointestinal digestion. Food Chem. 240, 156-164.

Rafe, A., Sadeghian, A., Zohreh, S., 2017. Physicochemical, functional, and nutritional characteristics of stabilized rice bran form tarom cultivar. Food Sci. Nutr. 5, 407-414.

Rocha, C., Goncalves, M.P., Teixeira, J.A., 2011. Immobilization of trypsin on spent grains for whey protein hydrolysis. Process Biochem. 46, 505-511.

Singleton, V.L., Orthofer, R., Lamuela-Raventós, R.M., 1999. Analysis of total phenols and other oxidation substrates and antioxidants by means of folin-ciocalteu reagent. Methods Enzymol. 299, 152-178.

Tavano, O.L., 2013. Protein hydrolysis using proteases: an important tool for food biotechnology. J. Mol. Catal. B Enzym. 90, 1-11.

Thamnarathip, P., Jangchud, K., Nitisinprasert, S., Vardhanabhuti, B., 2016. Identification of peptide molecular weight from rice bran protein hydrolysate with high antioxidant activity. J. Cereal. Sci. 69, 329-335.

Uraipong, C., Zhao, J., 2016. Rice bran protein hydrolysates exhibit strong in vitro $\alpha$-amylase, $\beta$-glucosidase and ACE-inhibition activities. J. Sci. Food Agric. 96, 1101-1110.

Wang, X., Chen, H., Fu, X., Li, S., Wei, J., 2017. A novel antioxidant and ACE inhibitory peptide from rice bran protein: biochemical characterization and molecular docking study. LWT - Food Sci. Technol. (Lebensmittel-Wissenschaft -Technol.) 75, 93-99.

Wanyo, P., Meeso, N., Siriamornpun, S., 2014. Effects of different treatments on the antioxidant properties and phenolic compounds of rice bran and rice husk. Food Chem. 157, 457-463.

Wattanasiritham, L., Theerakulkait, C., Wickramasekara, S., Maier, C.S., Stevens, J.F., 2016. Isolation and identification of antioxidant peptides from enzymatically hydrolyzed rice bran protein. Food Chem. 192, 156-162.

Wu, N.N., Li, H.H., Tan, B., Zhang, M., Xiao, Z.G., Tian, X.H., Gao, K., 2018. Free and bound phenolic profiles of the bran from different rice varieties and their antioxidant activity and inhibitory effects on a-amylose and a-glucosidase. J. Cereal. Sci. 82, 206-212.

Yang, Y., Guanjun, T.A.O., Ping, L.I.U., Liu, J.I.A., 2007. Peptide with angiotensin Iconverting enzyme inhibitory activity from hydrolyzed corn gluten meal. J. Agric. Food Chem. 55, 7891-7895.

Zhao, Q., Xiong, H., Selomulya, C., Dong, X., Zhong, H., Wang, S., Sun, W., Zhou, Q., 2012. Enzymatic hydrolysis of rice dreg protein: effects of enzyme type on the functional properties and antioxidant activities of recovered proteins. Food Chem. 134, 1360-1367 